\title{
Tracking and nowcasting of convective cells using remote sensing data from radar and satellite
}

\author{
KIRSTIN KOBER* and ARNOLD TAFFERnER
}

Deutsches Zentrum für Luft- und Raumfahrt, Institut für Physik der Atmosphäre, Oberpfaffenhofen, Germany

(Manuscript received April 7, 2008; in revised form November 21, 2008; accepted January 9, 2009)

\begin{abstract}
At the Deutsches Zentrum für Luft- und Raumfahrt (DLR) an algorithm named "Cb-TRAM" has been developed to identify, track, and nowcast thunderstorm clouds in different development stages (ZINNER et al., 2008). The tracking of detected clouds is based on the so-called "pyramidal image matcher". Applying this tracking algorithm to radar data resulted in the development of the radar tracker Rad-TRAM. Rad-TRAM is introduced here and used in parallel with Cb-TRAM for three cases of thunderstorm occurrence in Central Europe. The purpose of the study is threefold. Firstly, to test the ability of both trackers to track these features. Secondly, to compare position and tracks of cloud and radar cells in a visual and a statistical analysis by overlaying cell structures of both systems. Thirdly, to test the nowcasting performance of both trackers against extrapolations based on Lagrangian persistence. It is found that both trackers are able to detect and track the thunderstorms. For all observation times a percentage of about $70 \%$ of the satellite detected clouds in development stage "mature" overlap with radar cells when applying a minimum overlap criterion, i.e. one pixel of both cell types. Furthermore, it is found that Cb-TRAM as well as Rad-TRAM nowcasts for 15, 30, 45, and 60 minutes outperform extrapolations based on persistence. The results are discussed taking into account the different data bases used and specific thresholds in both algorithms.
\end{abstract}

\begin{abstract}
Zusammenfassung
Am Deutschen Zentrum für Luft- und Raumfahrt (DLR) wurde ein Algorithmus mit Namen "Cb-TRAM" entwickelt (ZINNER et al., 2008), um Gewitter in verschiedenen Entwicklungsstadien zu erkennen, zu verfolgen und vorherzusagen. Die Verfolgung der identifizierten Zellen basiert auf dem sogenannten "Pyramidal Image Matcher". Durch Anwendung dieses Matching-Verfahrens auf Radardaten entstand der Radartracker RadTRAM. Rad-TRAM wird in dieser Arbeit vorgestellt und zusammen mit Cb-TRAM auf drei verschiedene Gewittersituationen über Mitteleuropa angewandt. Die Studie verfolgt drei Aspekte. Erstens, zu testen inwiefern die Tracker die Gewitter in den drei Fällen detektieren und verfolgen können. Zweitens, die Position und Spuren der erkannten Wolken- und Radarzellen zu vergleichen, indem sowohl eine visuelle als auch eine statistische Analyse der Überlagerung durchgeführt wird. Und drittens, die Qualität der Kürzestfristprognosen (Nowcasting) beider Systeme zu testen, indem sie mit der auf Lagrangescher Persistenz basierenden Prognosen verglichen wird. Es zeigt sich, dass beide Tracker die Gewitter gut erkennen und verfolgen können. Für eine minimale Überlappung von einem Pixel zwischen Wolken- und Radarzellen enthalten im Mittel über alle betrachteten Zeiten $70 \%$ aller Satellitenwolken im ausgewachsenen Entwicklungsstadium ein Radarzellenpixel. Die Qualität der Vorhersagen sowohl von Cb-TRAM als auch die von Rad-TRAM zeigen für die Vorhersagezeiten 15, 30, 45 und 60 Minuten bessere Ergebnisse als die auf Persistenz basierenden Extrapolationen. Die Ergebnisse werden in Bezug auf die verschiedenen Datensätze und der zugrundegelegten Schwellenwerte für die Detektion der Satelliten- und Radarzellen diskutiert.
\end{abstract}

\section{Introduction}

Thunderstorms, being the cause of heavy precipitation, hail, wind gusts and lightning, can disrupt public life regionally, impact road, rail and air transport and bring about human and economic losses. Despite increasing knowledge of the development principles of thunderstorms over the years through both new observation methods and sophisticated high resolution modelling, the ability to nowcast their evolution and propagation still lacks skill (i.e. WILHELMSON and WICKER, 2001; WILSON et al., 1998). On the one hand this is attributable to the short life time

\footnotetext{
${ }^{*}$ Corresponding author: Kirstin Kober, Deutsches Zentrum für Luft- und Raumfahrt, Institut für Physik der Atmosphäre, Oberpfaffenhofen, Germany, e-mail: kirstin.kober@dlr.de
}

of convective systems, about 20-30 minutes on average, which makes it difficult to forecast these weather features some hours in advance. On the other hand it stems from imperfect knowledge of the state of the atmosphere on the mesoscale, in particular regarding the three main ingredients which invoke thunderstorms, i.e. moisture availability, convective instability and lift. Therefore, present nowcasting systems mainly rely on extrapolating location and growth of thunderstorms already observed by satellite, radar and lightning into the future (WILSON et al., 1998). Several tracking and nowcasting systems based on this technique have been built in the past. They are either based on radar data like TITAN (DIXON and WIENER, 1993), COTREC/TREC (MECKLENBURG et al., 2000), CONRAD (LANG, 2001) or TRACE3D (HANDWERKER, 2002) or on satellite data like MASCOTTE (CARVALHO 
and JONES, 2001) or RDT (MOREL and SENESI, 2002), as these data sets are available almost in real time and at high spatial and temporal resolution.

Along with these the satellite data-based cloud tracker Cb-TRAM (Cumulonimbus Tracking and Monitoring) has been developed at the Institute of Atmospheric Physics of the Deutsches Zentrum für Luft- und Raumfahrt (DLR) (ZINNER et al., 2008). It features a novel tracking technique based on the pyramidal image matcher (see also MANNSTEIN et al., 1999; KEIL and CRAIG, 2007). This algorithm takes the spatial scale of detected cells into account by applying a stepwise procedure in which for each image pixel a displacement vector is calculated as the sum of displacements for all scales treated, starting from large to small scales. Applying Cb-TRAM for several thunderstorm occurrences in Central Europe has proven this technique to be able to track successfully long-lived convective clouds for several hours. This result suggested the application of this tracking technique to radar data and resulted in the development of the radar tracker Rad-TRAM. In this paper, both trackers are applied to propagating convective cells in parallel in order to

- test their ability to track these features,

- compare position and tracks of cloud and radar cells,

- nowcast convective cloud and radar cells and compare their quality with that of nowcasts generated with a Lagrangian persistence assumption.

ROBERTS and RUTLEDGE (2003) already investigated a combined use of radar and satellite data and found that skill increases in nowcasting storm initiation and growth. This result and other data combinations found in expert systems (e.g. Nimrod/GANDOLF (GOLDING, 1998; PIERCE et al., 2000) and AutoNowcaster (MUELLER et al., 2003) will be considered in the integrated system for nowcasting severe weather which is currently under development at DLR. As this work focuses on tracking and nowcasting of two tracking systems and not on forecasting of the entire convective life cycle (initiation, growth and decay) these works are not described in detail.

In the next section, both trackers are described and details are given regarding the common tracking algorithm, the data basis, the detection algorithms and critical thresholds. Thereafter, cases of application are described and a visual (section 3 ) and a statistical analysis (section 4) is carried out where the cloud cells detected by the cloud tracker Cb-TRAM and the precipitation cells detected by Rad-TRAM are investigated in parallel. Finally, the quality of short-range forecasts up to one hour of heavy precipitation cells provided by RadTRAM (radar cells in the following) and thunderstorm cells provided by $\mathrm{Cb}$-TRAM (cloud cells in the following) are analysed with conventional quality measures (section 5).

\section{Cb-TRAM and Rad-TRAM algorithms}

The algorithms used in Cb-TRAM and Rad-TRAM consist of four main procedures: extraction of the motion field, detection, tracking and nowcasting. The algorithms used in Cb-TRAM are described in detail by ZINNER et al. (2008). Here, the working principles of the Cb-TRAM algorithms common to both trackers are outlined briefly. Differences in the trackers which concern mostly the detection part are described in detail.

\subsection{Data}

The Cb-TRAM algorithm uses three data channels from the Meteosat 7 or 8 SEVERI instrument, i.e. the high resolution visible (HRV), the infra-red $10.8 \mu \mathrm{m}$ (IR), and the infra-red $6.2 \mu \mathrm{m}$ (water vapour, WV) channels. Over Central Europe the spatial resolution of the HRV channel is of about $1.5 \mathrm{~km} \times 1.5 \mathrm{~km}$ and for IR and WV of $5 \mathrm{~km} \times 5 \mathrm{~km}$. In addition, the ECMWF model analysis is used for calculating the height of the tropopause based on the current temperature at every image pixel. The analysis is provided daily at $0,6,12$ and 18 UTC. It has to be considered that satellite measurements include a parallax error resulting from the viewing angle of Meteosat. The parallax error increases with geographical latitude and cloud height and can cause a displacement of about $10-15 \mathrm{~km}$ to the north with respect to the true location of the storm.

The databasis used for the radar tracker Rad-TRAM is the European radar composite issued by the German Weather Service (DWD). It consists of radar reflectivities given in $\mathrm{dBZ}$ with a horizontal resolution of $2 \mathrm{~km}$ x $2 \mathrm{~km}$ and encompasses an area of $1800 \mathrm{x} 1800 \mathrm{~km}^{2}$ (Fig. 1). This spatial coverage is unique for radar data in Europe and therefore chosen in this study.

The radar reflectivity values are observations received from 3-dimensional radar scans of various radars across Central Europe. As there is no common scan strategy for all countries not every value at every pixel represents the value of the lowest scan in the vertical where an echo is found (as it is defined in Germany), but also the highest values as representatives are possible. In case observations from two or more radars overlap at one point, the maximum of these observations is chosen (pers. comm. with DWD). Also, the national constituents do not have identical level boundaries but are factitiously adjusted during the composite procedure to the six reflectivity classes used by DWD (Tab. 1).

The radar composite provides a synopsis of the weather situation with regards to precipitation over a large domain, but individual pixel values are not representative of the actual microphysical process in place. Several factors influence the observations. The scanning mode changes from radar to radar. The lowest scan in mountainous regions might see the core precipitation processes of the cloud while over flat land it might see the precipitation falling out of the cloud. Due to beam 


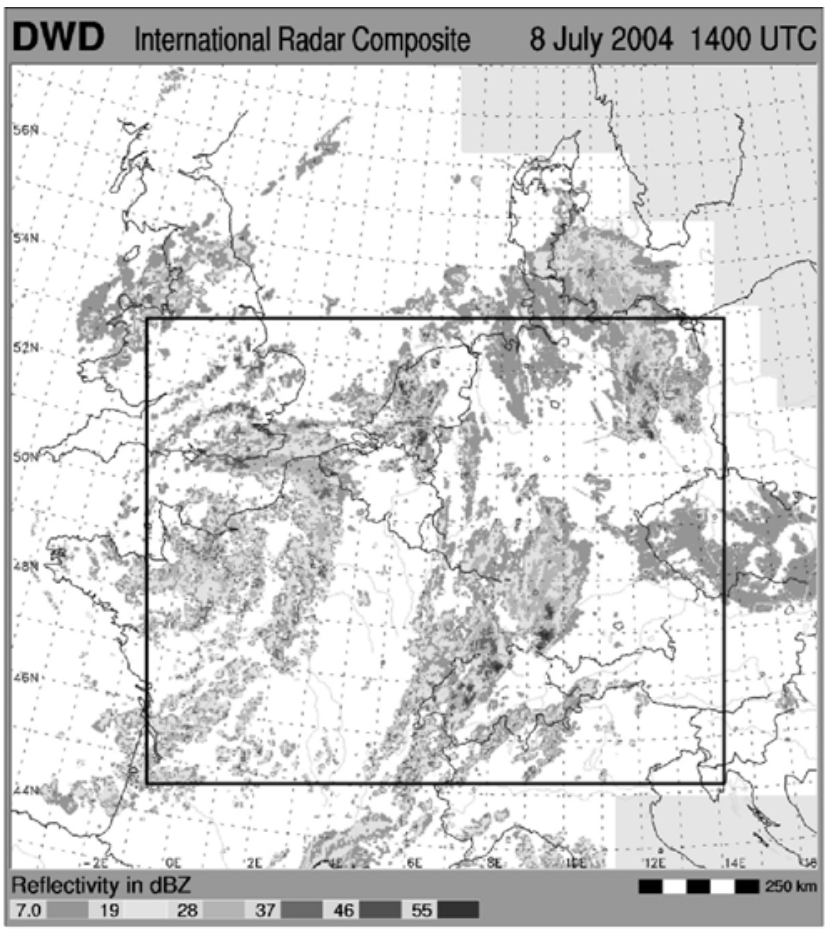

Figure 1: 8 July 2004, 14:00 UTC: European radar composite (DWD) with the Rad-TRAM domain (black).

Table 1: Reflectivity classes of European radar composite (DWD).

\begin{tabular}{ccl}
\hline $\begin{array}{c}\text { reflectivity } \\
(\mathrm{dBZ})\end{array}$ & colour & approx. precipitation types \\
\hline$>55.0$ & blue & $\begin{array}{l}\text { very heavy rain and hail, large } \\
\text { hail possible }\end{array}$ \\
$46.0-55.0$ & violet & very heavy rain, hail possible \\
$37.0-45.5$ & red & moderate to heavy rain \\
$28.0-36.5$ & orange & moderate rain \\
$19.0-27.5$ & yellow & light rain \\
$7.0-18.5$ & green & very light rain \\
\hline
\end{tabular}

blocking there can be gaps in the composite, i.e. pixels with no identified radar measurement. Data quality and resolution change with distance from the radar, the data processing is not standardized among the radars in $\mathrm{Eu}-$ rope. E.g. sometimes white spots appear in the composite over France which are indeed observations of very high reflectivity. These facts resulting in an inhomogeneous field must be considered when interpreting the radar composite in a quantitative sense.

\subsection{Extraction of the motion field}

In the first part of the algorithm displacement vectors for all pixels are derived of a pair of images in order to yield a best match of both. The images treated by Cb-TRAM or Rad-TRAM are two consecutive satellite or radar images, respectively, spaced 15 minutes apart. In contrast to feature-based matchers which select a certain pattern in one image and search for it within a target area of the second one, here an area-based matcher is used: for each pixel position, a displacement vector is calculated such that the local squared difference between both images is minimized, or optionally, the local correlation maximized. In order to take into account that small-scale motions in clouds, or the corresponding precipitation fields, are often superposed on the large scale flow, as e.g. in moving fronts, the "pyramidal matcher" has been developed which handles this scale dependency. In a stepwise procedure, lower resolution images representing larger scales are created by averaging over $2^{n}$ pixels with $n$ being the number of successive iterations. For every pixel location, a displacement vector is computed by shifting one image within the range of $+/-2$ pixel elements in both horizontal dimensions such that the best fit to the other image is calculated. After each step, the displacement vector field is interpolated to the full resolution grid and the image to be matched by this vector field is advanced. These steps are repeated at successively finer scales with decreasing $n$. Finally, the displacement vector field is the sum of the displacement vectors derived at the different resolutions.

\subsection{Detection}

In Cb-TRAM, three types of development stages of thunderstorm clouds are treated: strong local development (also referred to "convection initiation"), rapid cooling and mature phase. For detection of convection initiation, a positive change in cloud amount, i.e. increase in cloud area inferred from the HRV channel, must be supported by a cooling in the IR. A corresponding cloud mask is formed for pixels meeting this condition. For development type "rapid cooling", cloud developments with a clear signal of cooling inferred from the WV channel form the second cloud mask. Detection of mature convective cells is bound to areas exhibiting a WV temperature close to or smaller than the tropopause temperature in combination with a large gradient of reflectivity in the HRV channel. The HRV is used here in order to distinguish the updraft regions within thunderstorms from the large cirrus anvil. Finally, all three masks are combined into one mask composed of all detected cells which is tracked in the following.

In Rad-TRAM convective cells are identified as areas reaching or exceeding the threshold of $37 \mathrm{dBZ}$ (red coloured pixels in Fig. 1). Using this threshold includes cells representing deep convection leading to middle to heavy precipitation. $37 \mathrm{dBZ}$ ensure that the cells have a proper size and lifetime to be tracked. Also further development to higher reflectivities is possible. For $37 \mathrm{dBZ}$ heavy precipitation is most likely and the occurrence of hail is probable if $55 \mathrm{dBZ}$ are exceeded. Tests with the nearest reflectivity classes of 28 and $46 \mathrm{dBZ}$ show that the chosen threshold is a proper solution. With the threshold of $46 \mathrm{dBZ}$ cells with shorter lifetimes and therefore lower tracking possibilities are identified. A threshold of $28 \mathrm{dBZ}$ leads to a larger number of larger cells, also with difficulties in producing tracks. It has to be considered, that other processes than convection can 
cause a radar signal of $37 \mathrm{dBZ}$, as e.g. frontal circulations or uplift at sloping orography.

In both algorithms a cell must consist of at least 3 neighbouring pixels. Due to the applied circular smoothing in the detection algorithms, such small cell elements are extended to at least 21 contiguous pixels.

\subsection{Tracking}

Detected convective cells are tracked in consecutive images by using the displacement vectors derived in the pyramidal image matcher together with the method of maximum overlap. The short refresh cycle of 15 minutes for both satellite and radar images makes this approach feasible. Based on the detected cells at time $t-1$ the motion field as calculated by the image matcher is used to estimate the position of the cells at observation time $t$ (first guess patterns). The extrapolated cells are overlaid with the observed cells at time $t$. The observed cell which shows the maximum overlap with the first guess pattern adopts the cell's history. If no overlap is found, a new cell is created and the old one disappears. Merging of cells is possible when an overlap of the observed cell is found with more than one first guess cell. In this case the cell with the maximum overlap is continued while the other overlapping cells stop existing. Also, cell splitting is possible. If one first guess pattern overlaps with two (ore more) cells, the cell with the maximum overlap with an observed cell at time $t$ inherits the cell's history while the other is newly generated. Splitting and merging in the algorithm is not necessarily related to the splitting and merging of thunderstorm cells in reality, but may in circumstances be resultant from the special thresholds used. Lines connecting the cell's centre of gravity at consecutive times display the cell's track. Here the centre of gravity is the intensity weighted centre of the cell. Sudden changes in cell size, i.e. caused by splitting or merging, can be seen as kinks in the tracks and should not be looked at as failure of the tracking procedure. For every cell a file is created with information about the cell number (identity), the observation times, the pixel indices covered by the cell (cell size), the coordinates of the centre of gravity and the nowcasting positions. In the Cb-TRAM algorithm, the tracked clouds in addition carry information about the development stage that can change along the history of a tracked cell.

\subsection{Nowcasting}

A further application of the derived displacement vector field is the generation of short range forecasts. Extrapolating the pixel positions of the detected cells for four time steps provides nowcasts up to one hour. Using the displacement vector field for every cell pixel instead of translating the cell as a whole, e.g. by applying one motion vector to the cell's centre, enables the cell to change size and shape, thereby taking into account the trend.

\section{Case studies: visual analysis}

For the analysis of the performance of both trackers, a visual analysis of detected cloud and radar cells is carried out first. In the following, a short description of the cases selected together with some illustrated examples of detected convective cloud and radar cells is provided. For the visual analysis the cell structures detected by both trackers are overlaid for every observed timestep. As both tracking systems treat thunderstorm cells it is expected that due to the characteristic cloud development and attendant heavy precipitation consistent results are found, i.e. satellite and radar cells in about the same place resulting in full or at least partial overlap. In order to check whether the tracking algorithm works reliably for both trackers even over many hours, three different convective situations are analysed:

Case A: a single thunderstorm cell in the Alpine foothills on 8 July 2004

Case B: a significant cold frontal passage over Central Europe on 12 August 2004

Case C: local thunderstorms caused by heating over the Alps on 24 June 2005.

\subsection{Case A}

On 8 July 2004, an intense low pressure vortex initially situated south of England moved eastward over France during the course of the day. Ahead of this system a cold front extending from southern France over Switzerland and across Germany moved eastward. The signatures in the radar reflectivity field (Fig. 1) show the related frontal bands spiralling into the low pressure centre as well as the broad frontal band which is situated ahead of the upper-level trough.

Ahead of the eastward propagating cold front isolated thunderstorm cells formed in the afternoon hours. One of these cells is shown in the HRV image over southern Germany with the strongest development taking place north of the Lake of Constance at 14:00 UTC (Fig. 2a). Both cell types, i.e. detected from satellite imagery by Cb-TRAM (marked in red) and from radar composite by Rad-TRAM (in blue) can be seen. This thunderstorm cloud is identified by Cb-TRAM as a cell of type "mature". The cloud was first identified at 12:30 UTC west of the Lake of Constance and its later track is displayed by the red line. Within the cloud two cells with reflectivity values reaching at least $37 \mathrm{dBZ}$ are detected by Rad-TRAM. Fig. $2 b$ shows these cells together with the reflectivity field and the 30 and 60 minute nowcast. Notably, Cb-TRAM is capable of discriminating within the large thunderstorm cloud the strongest updraft region where also precipitation is maximized. The combination of different MSG channels for detecting mature convective cells obviously achieves the desired result. The visual inspection of the thunderstorm cloud alone would probably suggest a larger convective area, or at least another thunderstorm cell could be assumed to exist further north. 
(a)
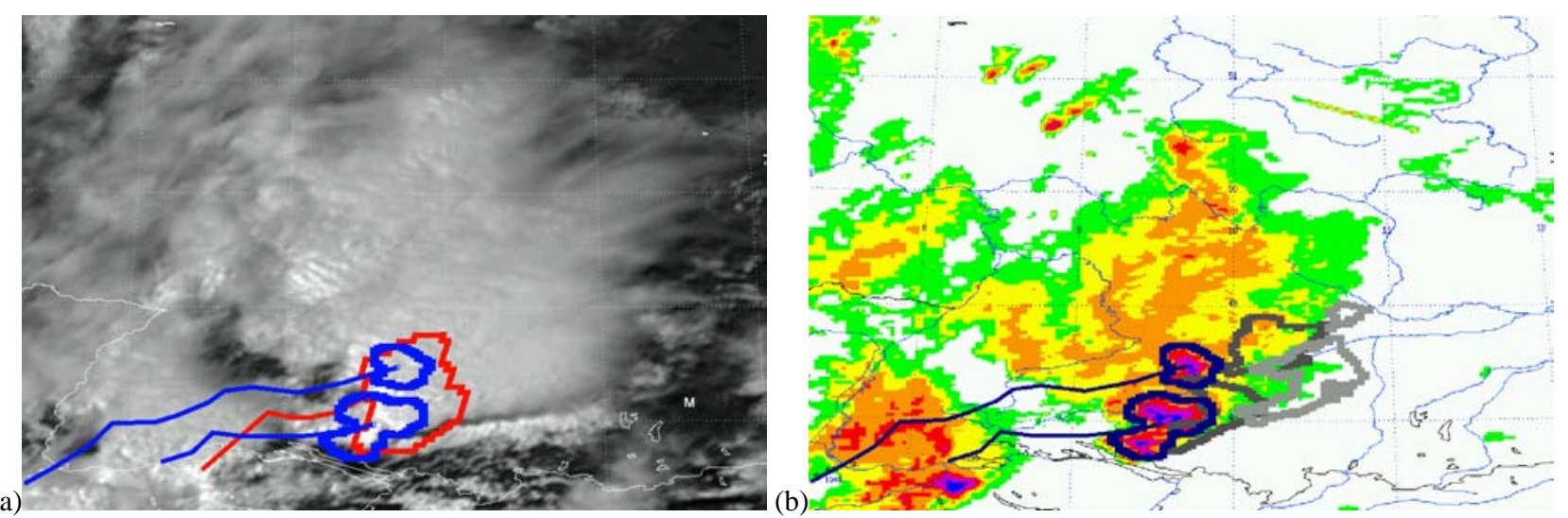

(c)

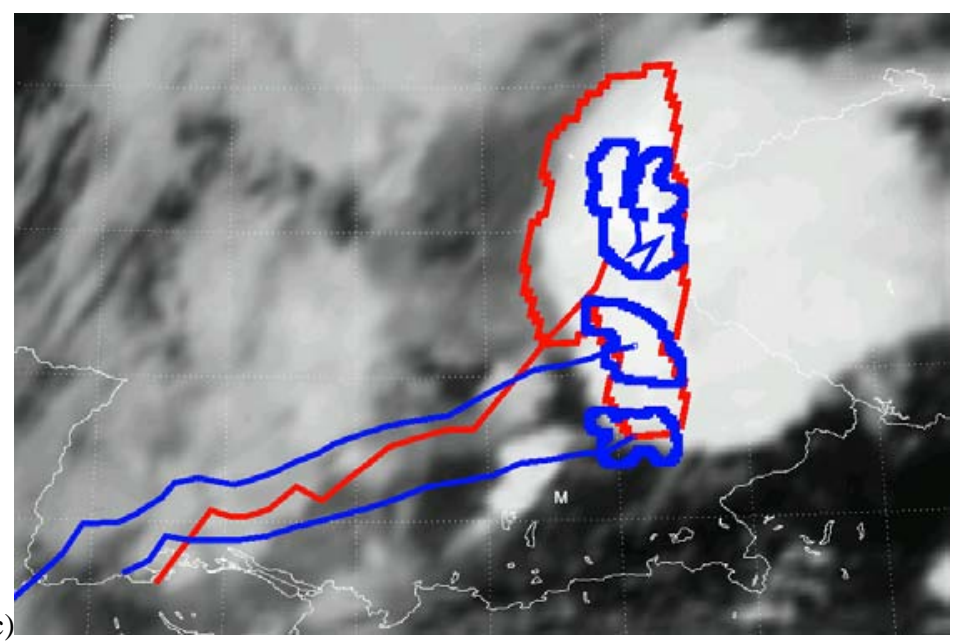

Figure 2: 8 July 2004: (a) 14:00 UTC: HRV data with Cb-TRAM and Rad-TRAM cell structures. Cb-TRAM cloud in red (stage 3), RadTRAM cells in blue. (b) 14:00 UTC: European radar composite (DWD) and Rad-TRAM analysis (black) and nowcast for 30 min (dark grey) and 60 min (light grey). (c) 17:00 UTC: IR data with Cb-TRAM (red) and Rad-TRAM cell structures (blue).

The convective feature had been tracked for two hours prior to this time and continues to exist for another three hours, as seen in the analysis of the monitored cloud and radar cells (Fig. 2c). The radar cells propagate roughly parallel to the cloud cell as the blue tracks indicate and continue to stay within the cloud with their centres located near the upstream side of the cloud. Such a displacement between the location of the updraft region with heaviest precipitation and the upper-level thunderstorm cloud is typically found in fast moving convective systems and is attributable to vertical shear in the wind field. The radiosonde observation from Munich (marked with "M" in Figs. 2a and 2c) at 12:00 UTC is consistent with this explanation, with near ground winds from the north-west with 5-10 knots increasing to 70 knots and turning to south-west at 10 to $12 \mathrm{~km}$. The tropopause is found at $11.5 \mathrm{~km}$ height and the convective available potential energy reaches $1000 \mathrm{~J} / \mathrm{kg}$. The thunderstorm cell propagates on average at a speed of $65 \mathrm{~km} / \mathrm{h}$. Such a propagation of thunderstorm cells is typically found in the northern pre-Alps and has been found already in previous studies based on lightning (HAGEN et al., 1999) and radar data (HAGEN et al., 2000). They normally originate in the area of the Lake of Constance and travel eastward along the northern foothills of the Alps guided by the upper-level flow.

An analysis of the detected cloud and radar cells at all time steps from 12:30 to 21:45 UTC leads to the conclusion that both Cb-TRAM and Rad-TRAM are able to detect and track the thunderstorm cloud together with the precipitation cells during their entire lifetime. This does not imply that the individual cells in the cloud persist for the entire time interval. It is possible that individual precipitation cells decay and new ones are generated at their place. These are identified by Rad-TRAM at the next time step and the old tracks are continued because they are within the forecast position of the old cells. Only a more detailed analysis with a higher resolution data base and ideally with the use of 3D radar data would make a distinction between the particular cells possible.

\subsection{Case B}

On 12 August 2004, an intense cold front propagated eastward across Central Europe. Ahead of the front, a line of thunderstorms developed starting at about noon and continued travelling ahead of the cold front until late in the evening when the cold front reached the 
Czech Republic (about 20:30 UTC). Fig. 3a shows the HRV Meteosat image as background together with the convective clouds detected by Cb-TRAM at $12 \mathrm{Au}-$ gust 2004, 16:00 UTC. While the broad cold frontal band stretches out over a large area of Central Europe, one can recognize clearly the pre-frontal cloud band where Cb-TRAM detects several individual thunderstorm cells. Also behind the cold front a convection line is apparent where some convective cells are identified by $\mathrm{Cb}$-TRAM as thunderstorm clouds. Fig. $3 \mathrm{~b}$ shows the same situation with the European radar composite. Cells detected by Rad-TRAM with reflectivity of at least $37 \mathrm{dBZ}$ are also found in the pre-frontal convection line. The path of the cells in the past time steps is again displayed as the connection line of the centres of gravity. Comparing both figures again shows agreement in cell positions.

\subsection{Case C}

On 24 June 2005, Central Europe was under the influence of a synoptic wave pattern with the trough axis situated to the west of France over the Atlantic and the centre of the ridge extending from Norway southward over the Alps to Central Italy. This wave pattern was almost stationary. Thunderstorms driven mainly by daytime heating developed in several regions of the Alps. Due to weak synoptic flow, these thunderstorms were almost stationary and short-lived. Fig. 4 shows an example of the convective situation at one point of time, an overlay of detected cloud and radar cells over the western Alps with the HRV image as background at 17:15 UTC. There are several cells detected by Cb-TRAM in stage "rapid growth" and "mature" and by Rad-TRAM. The different colours in the tracks of the Cb-TRAM cells over northern Italy and Austria indicate that these cells some time steps before were in a different development stage. In every mature thunderstorm cell, a radar cell is found which is smaller than the corresponding cloud cell. Cb-TRAM does not simply mark the whole thunderstorm cloud, but only those parts where convective updrafts are found, in good agreement with the actual locations of heavy precipitation. In the two rapidly developing regions (orange contours) precipitation is observed in the radar composite but has not yet reached the threshold of $37 \mathrm{dBZ}$. It is worth noting that the radar data here might not fully represent the real situation due to beam blocking by the high terrain.

\subsection{Summary of the visual inspection}

In all three cases, both trackers identify convective clouds and areas of heavy precipitation. The results fit well to the observer's subjective analysis. In synoptically driven environments, long-lived cells are tracked, e.g. on 8 July and 12 August 2004. Cell splitting and merging is handled by the tracking algorithm. Splitting has the effect that the centre of gravity of a cloud is suddenly displaced, appearing as a kink in the track, while (a)

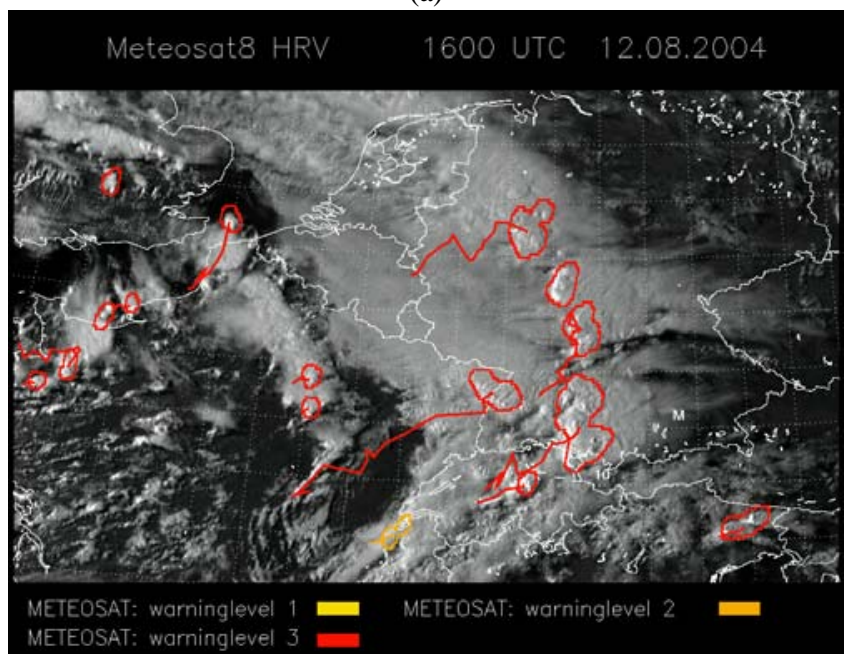

(b)

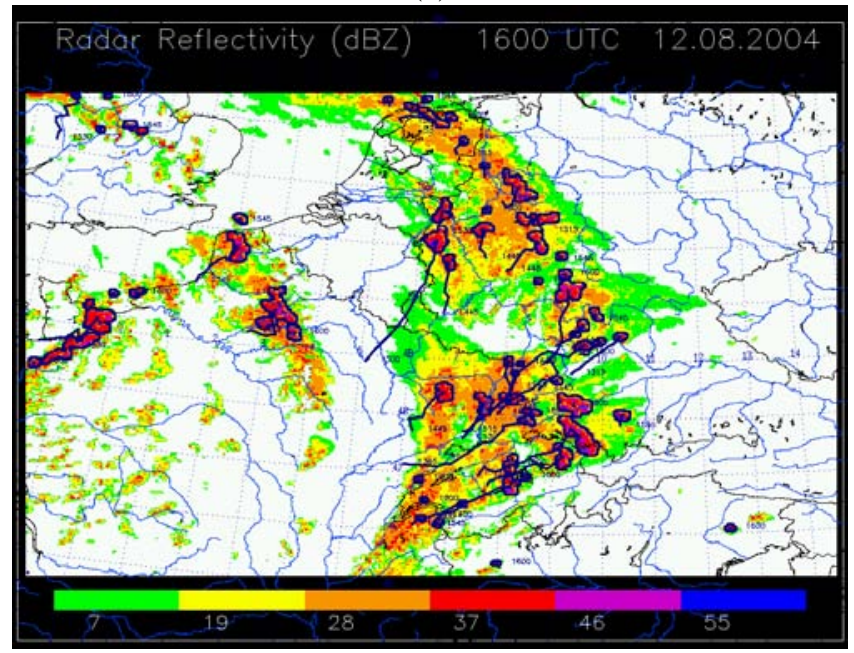

Figure 3: (a) 12 August 2004, 16:00 UTC: HRV data and Cb-TRAM cell structures. (b) 12 August 2004, 16:00 UTC: European radar composite (DWD) and Rad-TRAM cell structures.

at the same time, a new cloud appears near the splitting point (not shown). In the case of merging only the track belonging to the cell which has a larger overlap with the observed cell at the new time step is continued (e.g. Fig. 3a, over northern Germany).

The overlay of the cell contours of both trackers allows investigation of their relative positions. When assessing the observed overlap, it has to be considered that not for all Cb-TRAM clouds overlapping Rad-TRAM cells are expected as they represent different development stages during a thunderstorm's life cycle. Convection initiation is not connected to radar reflectivities of $37 \mathrm{dBZ}$ as in this development stage only initial growth of cumulus clouds is observed. These cumulus clouds have not yet produced hydrometeors detectable by radar (RoberTs and Rutledge, 2003). Clouds representing rapid vertical development can be expected to coincide more often with radar cells as it is already possible that these cumulus clouds cause precipitation result- 


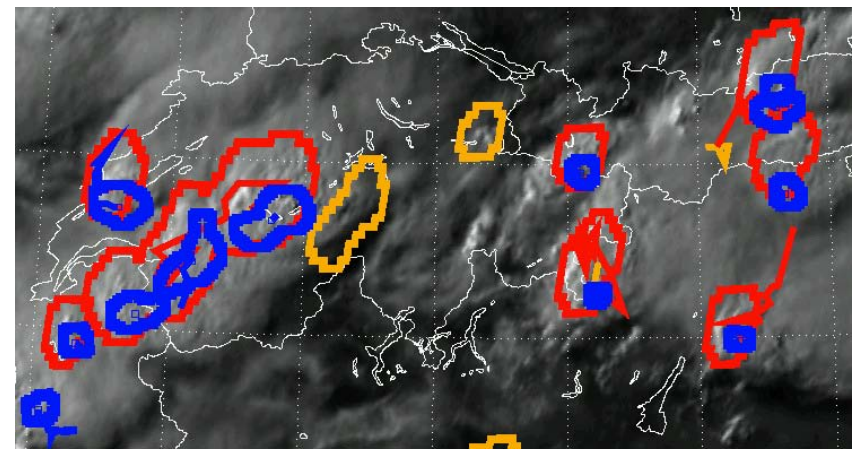

Figure 4: 24 June 2005, 17:15 UTC: HRV data with Cb-TRAM (red and orange) and Rad-TRAM cell structures (blue)(cut out of domain)

Table 2: Overlapping criterion: absolute values of $\mathrm{Cb}$-TRAM clouds overlapping with Rad-TRAM cells (SAT with RAD); separated to the different development stages.

\begin{tabular}{c|c|ccc} 
date & SAT with RAD & stage 1 & stage 2 & stage 3 \\
\hline 8 July 2004 & 92 & 3 & 43 & 46 \\
12 August 2004 & 149 & 4 & 42 & 103 \\
24 June 2005 & 104 & 1 & 42 & 61
\end{tabular}

ing in radar reflectivities at the threshold. Mature thunderstorms appear as deep convective clouds with heavy precipitation. However, during the decaying phase of a thunderstorm, heavy precipitation has ceased but the cirrus anvil is still identified as cloud of type "mature" by Cb-TRAM. Also precipitation cells appear without an identified convective cloud. This happens primarily when heavy precipitation occurs along the cold front obviously forced by frontal processes.

Differences among the cloud and precipitation cells can also be found as regards to the cells' area. In convective cases, the precipitation cell normally is smaller and shorter-lived than the cloud cell. There are areas where the cell detected by Rad-TRAM covers a larger area than the Cb-TRAM cloud (e.g. Figs. $3 \mathrm{a}$ and $3 \mathrm{~b}$ over France). These are obviously connected to weather situations of non-convective origin, e.g. frontal precipitation or orographic lift. Furthermore, the relative positions of the cells differ for different types of thunderstorms. In small, single, stationary, cells (24 June 2005, Fig. 4) the precipitation cells cover a smaller area within the mature thunderstorm cloud and appear anywhere within the cloud. In the cases of strong synoptic/mid-level flow on 8 July 2004 and 12 August 2004, the precipitation cores are predominantly found on the upstream side of the cloud cells (Figs. 3a and 3b). In larger organized structures (Fig. 3a and 3b over Germany) several small heavy precipitation cells can be observed in one cloud cell. This observation agrees very well with the concept of multicell thunderstorms (SCHIESSER et al., 1995). In the case of propagating thunderstorms, e.g. on 8 July 2004 (Fig. 2) and 12 August 2004 (Figs. 3a and 3b), long-lived cells are found in both the Cb-TRAM and Rad-TRAM analysis with almost parallel tracks for several hours. Long tracks do not necessarily imply long lifetimes of individual cells. The tracking algorithm might connect a decaying cell with a new cell in the neighbourhood, as location and resulting overlap are the crucial parameters for cell allocation.

\section{Case studies: statistical analysis}

In order to yield a more objective estimation of the consistency of both trackers, a statistical analysis is carried out. In this analysis, consistency is understood as an at least partial overlap of the two cell types. All Cb-TRAM clouds are counted for which at least at one time step during their lifetime an overlap with a radar cell is found. This analysis is carried out for all three cloud development stages. Finally, the counted numbers are related to the total number of all clouds found and for the respective development stages. Two different criteria for the definition of overlap are applied: firstly, the centre of gravity of the precipitation cell has to be within the cloud cell and secondly, there has to be a minimum overlap between both cell structures, chosen to be at least one pixel.

Tab. 2 lists for all three cases the total number of clouds (SAT) identified by Cb-TRAM and their distribution over the three development stages (stage 1 to 3 ). Every cloud is only counted once and attributed to the maximum development stage it reached during its lifetime. Rapidly growing cloud cells (stage 2) appear most frequently. Often convective cells are short-lived features with a lifetime of about 20 minutes (WILSON et al., 1998). They do not grow to tropopause levels vertically and thus cannot produce the characteristic anvil cloud. Correspondingly, these thunderstorm clouds are detected by Cb-TRAM up to maximum development stage 2 only.

Relatively small numbers are found for stage 1 in the three cases. Larger numbers could be expected because subjective reasoning suggests the number of starting convective clouds to be quite large. Two reasons account for the small numbers. Some of the clouds detected by $\mathrm{Cb}$-TRAM at stage 1 reach a higher development stage and are counted in the higher level group. It is observed that many clouds already meet the criteria for stage 2 at the time they are detected first. Of course it is desirable that Cb-TRAM detects all convective developments already at stage 1 , ideally to find all three stages for every mature thunderstorm. This is not possible due to the fast growth of convective clouds, about 10-15 minutes, where an observation frequency of 15 minutes will miss many developments at first stage. Also the selected detection thresholds in the HRV and IR channels, although tuned to catch early developments, might miss clouds. Not all convective clouds grow in place, but propagate during development, so an appropriate first guess field of motion is needed to track them. 
Table 3: Centre of gravity criterion: absolute values of Cb-TRAM clouds overlapping with Rad-TRAM cells (SAT with RAD); separated to the different development stages.

\begin{tabular}{c|c|ccc} 
date & SAT with RAD & stage 1 & stage 2 & stage 3 \\
\hline 8 July 2004 & 61 & 0 & 28 & 33 \\
12 August 2004 & 105 & 2 & 19 & 84 \\
24 June 2005 & 81 & 1 & 27 & 53
\end{tabular}

Table 4: Centre of gravity criterion: percentage of absolute values (Tab. 3) to total numbers (Tab. 2) (RAD/SAT); separated to the different development stages.

\begin{tabular}{c|c|ccc}
\hline date & RAD/SAT & stage 1 & stage 2 & stage 3 \\
\hline & & & & \\
8 July 2004 & $20.1 \%$ & $0.0 \%$ & $12.2 \%$ & $55.0 \%$ \\
12 August 2004 & $25.5 \%$ & $10.0 \%$ & $8.2 \%$ & $52.2 \%$ \\
24 June 2005 & $28.4 \%$ & $2.9 \%$ & $16.0 \%$ & $64.6 \%$ \\
\hline
\end{tabular}

Although this is accounted for in Cb-TRAM algorithm, certainly not every development is detected. Convection initiation not caused by daytime solar heating cannot be handled by the present version of Cb-TRAM which depends for stage 1 on the visible information in the HRV channel.

First it is investigated how many radar cells are found within these cloud cells when applying the centre of gravity criterion. Tab. 3 lists the total numbers, while in Tab. 4 the relative percentages are given as compared to the total number of all clouds (Tab. 2). At first sight, the total numbers of cloud cells which overlap with a radar cell (SAT with RAD in Tab. 3) are relatively low. Comparing the numbers for stages 1 and 2 in Tab. 2 and 3, the reason becomes clear. For stage 1 almost no radar cells with reflectivity of at least $37 \mathrm{dBZ}$ are found. Also for stage 2 , obviously the threshold of $37 \mathrm{dBZ}$ in radar reflectivity is relatively high, so only a few cases are found (16\% , Tab. 4). Most satellite/radar cell overlaps are found in stage 3 , the mature development phase. Here the relative percentages are 55 to $65 \%$.

When applying the minimum overlap criterion, i.e. overlap of at least one pixel, the numbers increase (Tab. 5 and 6). For stage 3, in about $70 \%$ of all mature satellite cells, radar cells with reflectivity above $37 \mathrm{dBZ}$ are found. Based on the visual analysis (Figs. 2 and 3), the percentage could be expected to be higher. However, the inspection of film sequences of the images produced at all time steps for the three cases often reveals the presence of short-lived cloud cells of type mature with no corresponding radar cell.

Several reasons account for the numbers. The most important one is the above mentioned problem of time resolution. Due to the short lifetime of convective cells it is quite likely that a 15 minute observation frequency will often miss the strongest development during the cloud physical process. Smaller cells often merge into
Table 5: Overlapping criterion: absolute values of Cb-TRAM clouds overlapping with Rad-TRAM cells (SAT with RAD); separated to the different development stages.

\begin{tabular}{c|c|ccc} 
& & & & \\
date & SAT with RAD & stage 1 & stage 2 & stage 3 \\
\hline 8 July 2004 & 92 & 3 & 43 & 46 \\
12 August 2004 & 149 & 4 & 42 & 103 \\
24 June 2005 & 104 & 1 & 42 & 61
\end{tabular}

Table 6: Overlapping criterion: percentage of absolute values (Tab. 5) to total numbers (Tab. 2) (RAD/SAT); separated to the different development stages.

\begin{tabular}{c|c|ccc}
\hline date & RAD/SAT & stage 1 & stage 2 & stage 3 \\
\hline & & & & \\
8 July 2004 & $30.5 \%$ & $23.1 \%$ & $18.7 \%$ & $76.7 \%$ \\
12 August 2004 & $36.2 \%$ & $20.0 \%$ & $18.2 \%$ & $64.0 \%$ \\
24 June 2005 & $36.5 \%$ & $2.9 \%$ & $24.9 \%$ & $74.4 \%$ \\
\hline
\end{tabular}

larger cells but only the identity of the larger cell is continued. So cloud cells at stage 3 can exist for which no overlapping radar cell has existed before merging. Restrictions in data quality (section 2.1) also lead to worse results in the analysis. The trackers can just be as good as the data they are based on. There might also be errors in detection of Cb-TRAM which is based on certain thresholds. Of course the thunderstorm's precipitation processes could just be too weak to produce a radar signal of $37 \mathrm{dBZ}$.

\section{Nowcasting - quality}

As described in section 2.5, Rad-TRAM and Cb-TRAM provide forecasts up to one hour based on the displacement vector field (example in Fig. 2b). To get a first idea of the forecasts' quality, the forecasts are compared to those produced under a Lagrangian persistence assumption where cell patterns are displaced by the calculated former displacement vector without changes in size and shape. The former displacement vector is the connection line of the cells' centres of gravity at time step t- 1 to t. The two different types of forecasts are overlaid with the actually observed pattern at the lead time. The corresponding hits, misses and false alarms are counted pixelwise. For every pattern the nowcasting quality measures 'False Alarm Ratio' (FAR), 'Probability of Detection' (POD) and 'Critical Success Index' (CSI) are calculated using the following equations ( $\mathrm{H}$ hits, $\mathrm{F}$ false alarms, $\mathrm{M}$ misses) (DIXON and WIENER, 1993):

$$
\begin{aligned}
& F A R=\frac{F}{H+F} \\
& P O D=\frac{H}{H+M}
\end{aligned}
$$


(a)

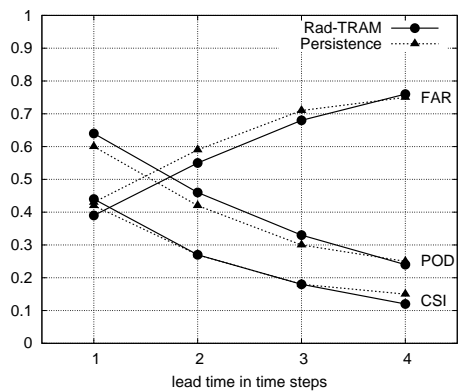

(b)

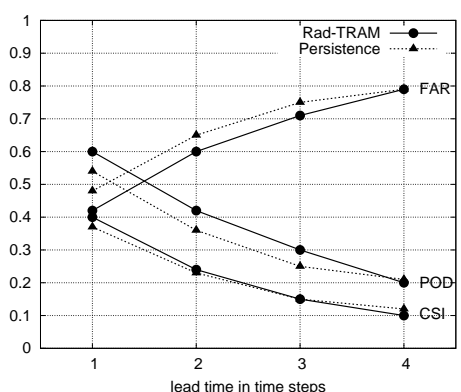

(c)

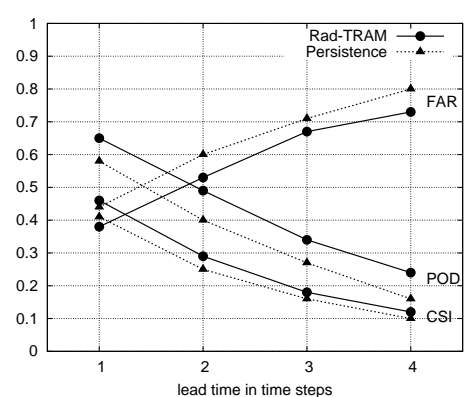

Figure 5: Nowcasting quality Rad-TRAM and Lagrangian persistence, (a) 8 July 2004, (b) 12 August 2004 and (c) 24 June 2005.

(a)

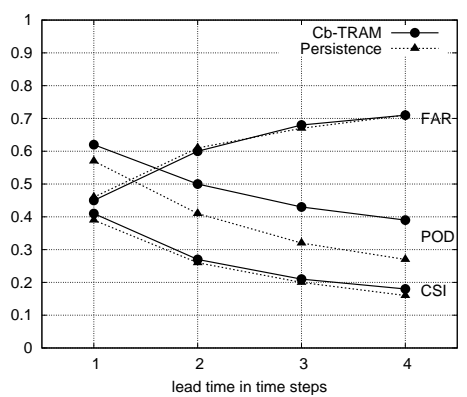

(b)

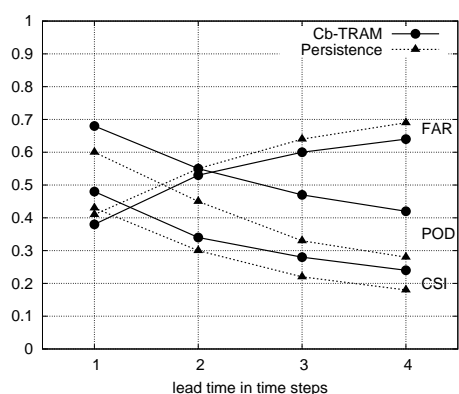

(c)

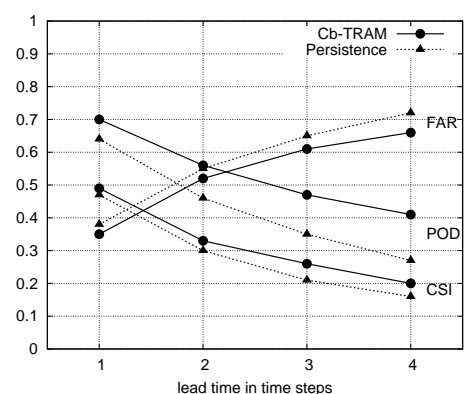

Figure 6: As in Fig. 5, but for Cb-TRAM.

$$
C S I=\frac{H}{M+H+F}
$$

For the three investigated cases, the quality measures are calculated as mean values over all times for which clouds (or radar cells) exist. Only clouds and cells are used for which a verification after 15, 30, 45 and 60 minutes forecast time is possible. As explained in section 2.5 a cell has a minimum size of 21 contiguous pixels.

The results for both trackers show a decrease in forecast quality with increasing lead time for all days (Fig. 5 for Rad-TRAM and Fig. 6 for Cb-TRAM), i.e. decreasing POD and CSI and increasing FAR with increasing lead time. The forecasts provided by the trackers show at almost all times better results than the persistence based forecasts for all three quality measures (i.e. higher POD and CSI and lower FAR). Only in Fig. 5a and 5b after four time steps (60 minutes) the CSI for persistence is slightly better than for the Rad-TRAM nowcasts. Limiting the forecast horizon to one hour is suggested in literature for extrapolating techniques (MUELLER et al., 2003; WILSON et al., 1998; WILSON, 2003). They argue, that the quick average development of these systems cannot be rendered by simple extrapolation techniques. Furthermore differences among the different extrapolating techniques disappear after this time period. The results for the three investigated cases do not support their argument consistently. Especially the one hour forecasts for $\mathrm{Cb}$-TRAM show noticeable differences to the persistence based forecasts (Figs. 6b and c), whereas the Rad-TRAM forecasts have about the same reduction in skill as the persistence after one hour (Fig. 5).

Analyzing the Figs. 5 and 6 reveals that the skill scores relative to the persistence-based forecasts appear to be better for Cb-TRAM. The differences even increase with lead time (Figs. 6b and 6c). As the tracking algorithms and the nowcasting procedures are the same in RadTRAM and Cb-TRAM, the reason must stem from the data basis. A possible explanation is that the WV images used in the matching algorithm in Cb-TRAM provide smooth and time-consistent cloud features from which quite accurate displacement vectors can be derived. These are then used for nowcasting the detected clouds. The radar imagery in contrast is not as smooth and more variable. On the one hand due to the shorterlived cells of heavy precipitation which are also smaller in size than the respective clouds in the WV channel, and on the other because of the lower data quality (section 2.1).

\section{Conclusions and outlook}

The development of the new radar tracker Rad-TRAM which is based on the pyramidal image matching algorithm of the already existing cloud tracker Cb-TRAM enabled the use of both trackers in parallel in cases of thunderstorm occurrence. In the visual analysis of tracked cloud features from satellite and precipitation features from radar the two algorithms consistently show reasonable agreement in the three investigated cases. In the statistical analysis the precipitation cells 
tracked by Rad-TRAM were investigated with respect to the different development stages of the convective clouds discriminated by Cb-TRAM. Applying a criterion of minimum overlap among convective clouds and precipitation cells numbers of about $70 \%$ on average are found, when satellite clouds have reached a mature thunderstorm stage. In contrast, during the convection initiation stage, less than $15 \%$ of the radar cells overlap with the clouds.

The quality of nowcasts for $15,30,45$, and $60 \mathrm{~min}$ utes provided by $\mathrm{Cb}$-TRAM and Rad-TRAM was found to outperform extrapolations based on the Lagrangian persistence assumption. Obviously, the pixel-based displacement vector field calculated by the image matching procedure which takes the scales of the detected features into account provides a better guess of future motion. Therefore, the forecast skill of Cb-TRAM and RadTRAM is promising and fits quite well into the tendencies and values that are found for other forecasts based on extrapolation techniques (e.g in the radar tracker TITAN (WILSON et al., 1998) or in the Sydney Forecast Demonstration Project (EBERT et al., 2004).

The parallel use of both trackers is one further step in the set-up of an integrated operational system for nowcasting severe weather which is currently under development at DLR. By using both kinds of remote sensing data, there is the advantage of being able to observe the same weather feature from different viewing geometry and with respect to the different physical quantities during the lifecycle of a thunderstorm. Such a combined observation with even higher quality radar data (higher spatial and temporal resolution, 3D) will be further exploited to achieve a better description of a weather feature to improve nowcasting (TAFFERNER et al., 2008).

\section{Acknowledgments}

The authors thank DWD for providing the European radar composite. Meteosat data are copyrighted by EUMETSAT. We also acknowledge the reviewers for their helpfull comments.

\section{References}

Carvalho, L., C. Jones, 2001: A satellite method to identify structural properties of mesoscale convective systems based on the maximum spatial correlation tracking technique (MASCOTTE). - J. Appl. Meteor. 40, 1683-1701.

DIXON, M., G. WIENER, 1993: TITAN: Thunderstorm Identification, Tracking, Analysis and Nowcasting - A Radarbased Methodology. - J. Atmos. Oceanic Technol. 10, 785797.

Ebert, E.E., L.J. Wilson, B.G. Brown, P. Nurmi, H.E. BROOKS, J. BALly, M. JAENEKE, 2004: Verification of Nowcasts from the WWRP Sydney 2000 Forecast Demonstration Project. - Wea. Forecast. 19, 73-96.

Golding, B.W., 1998: Nimrod: A system for generating automated very short range forecasts. - Meteorol. Appl. 5, $\underline{1-16 .}$
Hagen, M., B. Bartenschlager, U. Finke, 1999: Motion Characteristics of Thunderstorms in Southern Germany. - Meteorol. Appl. 6, 227-239.

Hagen, M., H.-H. SCHIESSER, M. Dorninger, 2000: Monitoring of Mesoscale Precipitation Systems in the Alps and the Northern Alpine Foreland by Radar and Rain Gauges. - Meteor. Atmos. Phys. 72, 87-100.

HANDWERKER, J., 2002: Cell tracking with TRACE3D - a new algorithm. - Atmos. Res. 61, 15-34.

KEIL, C., G.C. CRAIG, 2007: A Displacement-Based Error Measure Applied in a Regional Ensemble Forecasting System. - Mon. Wea. Rev. 135, 3248-3259.

LANG, P., 2001: Cell tracking and warning indicators derived from operational radar products. - Proceedings of the 30th International Conference on Radar Meteorology, Munich, Germany, 245-247.

Mannstein, H., R. Meyer, P. Wendling, 1999: Operational Detection of Contrails from NOAA-AVHRR-Data. Int. J. Remote. Sens. 20, 1641-1660.

MECKLENBURG, S., J. Joss, W. SCHMID, 2000: Improving the nowcasting of precipitation in an Alpine region with enhanced radar echo tracking algorithm. - J. Hydrol. 239, 46-68.

MOREL, C., S. SENESI, 2002: A climatology of mesoscale convective systems over Europe using satellite infrared imagery I: Methodology. - Quart. J. Roy. Meteor. Soc. 128, 1953-1971.

Mueller, C., T. Saxen, R. Roberts, J. Wilson, T. Betancourt, S. Dettling, S. Oien, J. Yee, 2003: NCAR Auto - Nowcast System. - Wea. Forecast. 18, 545$\underline{561 .}$

Pierce, C.E., P.J. Hardeker, C. G. Collier, C.M. HAGGETT, 2000: GANDOLF: a system for generating automated nowcasts of convective precipitation. - Meteorol. Appl. 7, 341-360.

Roberts, R., S. Rutledge, 2003: Nowcasting Storm Initiation and Growth Using GOES-8 and WSR-88D Data. Meteorol. Appl. 7, 341-360.

Schiesser, H.H., R.A. Houze JR., H. Huntrieser, 1995: The Mesoscale Structure of Severe Precipitation Systems in Switzerland. - Mon. Wea. Rev. 123, 2070-2097.

Tafferner, A., C. Forster, M. HaGen, C. Keil, T. ZINNER, H. VOLKERT, 2008: Development and propagation of severe thunderstorms in the Upper Danube catchment area: Towards an integrated nowcasting and forecasting system using real-time data and high-resolution simulations. - Meteorol. Atmos. Phys. 101, 211-227.

Wilhelmson, R., L. WiCKER, 2001: Numerical Modelling of Severe Local Storms. - In: DoswelL, C.A.(Ed.): Severe Convective Storms. Meteor. Monogr. 28, 123-167.

Wilson, J.W., N.A. Crook, C.K. Mueller, J. Sun, M. DiXON, 1998: Nowcasting Thunderstorms: A Status Report. - Bull. Amer. Meteor. Soc. 79, 2079-2099.

Wilson, J.W., 2003: Thunderstorm nowcasting: past, present and future. - Preprints, 31st Conf. on Radar Meteorology, Seattle, WA, Amer. Meteor. Soc., J13-J19.

Zinner, T., H. MAnnstein, A. TAFFerner, 2008: CbTRAM: Tracking and monitoring severe convection from onset over rapid development to mature phase using multichannel Meteosat-8 SEVIRI data. - Meteor. Atmos. Phys. 101, 191-210, DOI 10.1007/s00703-008-0290-y. 